\title{
Aerosol nucleation spikes in the planetary boundary layer
}

\author{
J.-P. Chen ${ }^{1}$, T.-S. Tsai ${ }^{1}$, and S.-C. Liu ${ }^{1,2}$ \\ ${ }^{1}$ Department of Atmospheric Sciences, National Taiwan University, Taiwan \\ ${ }^{2}$ Research Center for Environmental Changes, Academia Sinica, Taiwan
}

Received: 27 August 2010 - Published in Atmos. Chem. Phys. Discuss.: 9 November 2010

Revised: 26 June 2011 - Accepted: 27 June 2011 - Published: 21 July 2011

\begin{abstract}
Photochemically driven nucleation bursts, which typically occur within a few hours after sunrise, often produce strong aerosol number concentration (ANC) fluctuations. The causes of such ANC spikes were investigated using a detailed aerosol model running in the parcel mode. Two potential mechanisms for the ANC spikes were proposed and simulated. The blocking of actinic flux by scattered clouds can significantly influence new particle production, but this does not cause strong fluctuations in the number of aerosols within sizes greater than the detection limit of our measurements. A more plausible mechanism is the turbulence eddy effect. Strong aerosol nucleation may occur in both updrafts and downdrafts, while the cloud formation at the boundary layer top strongly reduces the number of aerosols. As the number of aerosols is sensitive to turbulence eddy and cloud formation properties, a changing turbulence condition would result in large fluctuations in the evolution of ANC similar to that observed at the surface.
\end{abstract}

\section{Introduction}

Strong aerosol production in the planetary boundary layer (PBL) has been observed over various parts of the continents and oceans (cf. Dinger et al., 1970; Hegg et al., 1990; Covert et al., 1992; O'Dowd et al., 1998; Kulmala et al., 2004). How such productions occur deserves special attention as aerosols can influence human life in many aspects, such as air pollution, visibility, convective precipitation, as well as the climate impact through the modification of cloud structures (c.f. Ozkaynak and Thurston, 1987; Quinby-Hunt et al., 1997; Khain et al., 2005; Levin and Cotton, 2007; Albrecht, 1989; Charlson et al., 1992; Ackerman et al., 1993).

Correspondence to: J.-P. Chen

(jpchen@as.ntu.edu.tw)
Besides direct emission or atmospheric transport, the nucleation process is considered an important source of aerosol particles in the PBL. Aerosol nucleation in the PBL often occurs during the daytime in the form of bursts that typically take only a few hours to complete. Sometimes the duration can be less than one hour (Marti, 1990; Marti et al., 1997; Clarke et al., 1998; O'Dowd et al., 1998; Clement et al., 2001). Such an aerosol burst phenomena can be demonstrated with an event (Fig. 1a) observed during the spring of 2001 at the Shimen sampling site located in Northern Taiwan. The measurement by an aerosol size spectrometer TSI SMPS-3934 (sampling frequency of about $7 \mathrm{~min}$ ) showed a rapid increase in aerosol number concentration (ANC) after sunrise and reached a peak before noon. To rule out the possibility of aerosol increase due to long-range transport, one may further examine the fraction of freshly produced particles (here defined as those with diameter $<30 \mathrm{~nm}$ ). The nucleation mode particles do not stay very long in the smallest size range because of either fast condensation or being collected by larger particles. So, a fresh-to-total number ratio above about 0.4 (which may vary with the definition of fresh particles) is a good indication of a nucleation event. The one shown in Fig. 1 is apparently a nucleation burst as the "fresh" fraction increased simultaneously with the number production. Evolution of the complete particle size spectrum is shown in Fig. 1b, and we will return to this figure for more detailed discussions in the last section. Various modeling studies have shown that such nucleation bursts occur under clear or partly cloudy sky when photochemical production of sulfuric acid vapor is active (e.g. Harriton and Kreidenwise, 1998; Pirjola et al., 2000; Korhonen et al., 2004; Hellmuth, 2006a). However, the simulated aerosol number concentrations usually increase rather smoothly whereas the observed ones often contain many spikes, as shown in Fig. 1a. Such high-frequency spikes exist not only in the number concentration but also in the fresh-particle fraction. 

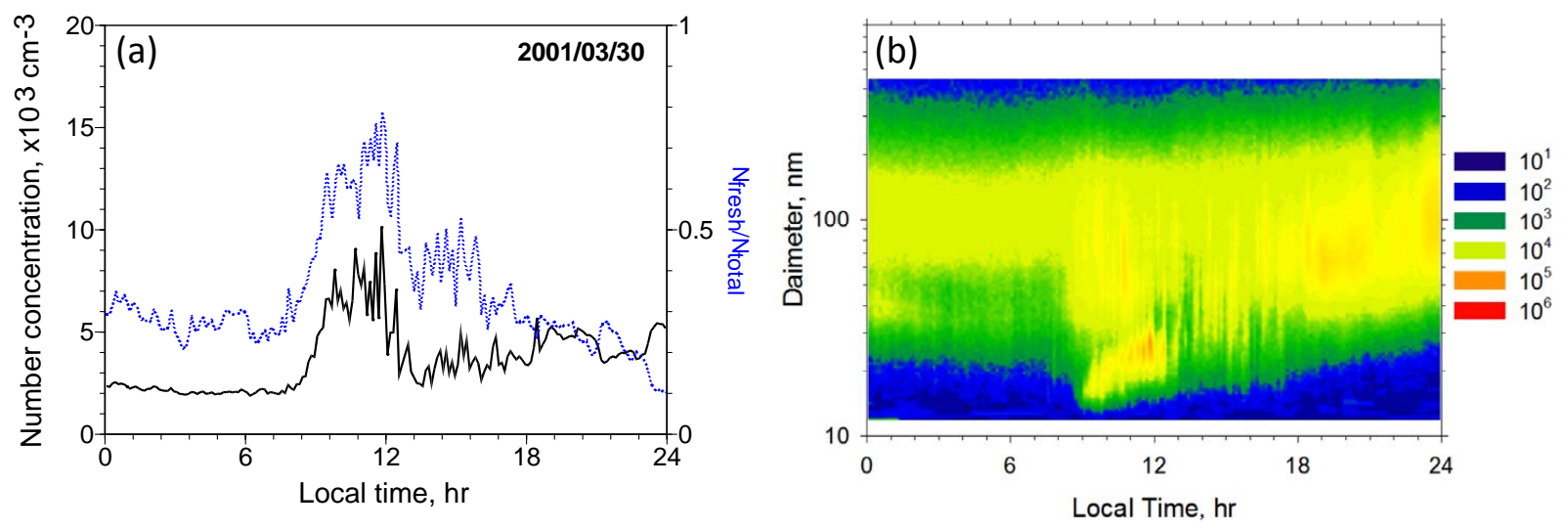

Fig. 1. An aerosol nucleation spikes event observed at a coastal site over Northern Taiwan on 30 March 2001. (a) Evolution of total aerosol number concentration (solid curve, left axis) and fraction of fresh particles (blue dotted curve, right axis); Fresh particles are defined as those with a diameter smaller than $30 \mathrm{~nm}$. (b) Evolution of aerosol particle size spectrum. The color bars show the particle number density $(d N / d \log D)$ in $\mathrm{cm}^{-3}$.

The measurement shown in Fig. 1 was taken during the ACE-Asia campaign in the spring of 2001. In this campaign the SMPS operated from 22 March to 1 May with 21 days of complete records. Among these 21 days, 12 were either rainy or overcast therefore not favorable for nucleation events. Five of the rest can be identified as having significant new particle formation, and their common meteorological conditions are clear to partly cloudy sky and moderate northeasterly winds with speeds generally below $7 \mathrm{~m} \mathrm{~s}^{-1}$. The pre-event aerosol concentrations were between 2000 and $3000 \mathrm{~cm}^{-3}$, which is above the typical values over the remote oceans but below that for polluted areas. Trace gas information is not available for the Shiman site. However, there is a near-by air-pollution monitoring station about $18 \mathrm{~km}$ away with a similar coastal geographic setting. This station is located in a small town with a population of just over 4100 at the time. It has some local traffic activities and thus cannot fully represent Shiman. Nevertheless, its measurements showed that these events were associated with daytime peak $\mathrm{PM}_{10}$ and ozone concentrations, indicating strong photochemical contribution to aerosol growth. In Fig. 2, the hourly air temperature and relative humidity from this air pollution monitoring station and UV-A radiation from a weather station $24 \mathrm{~km}$ away show that the days with nucleation bursts (blue dots) have distinctly larger diurnal variations in these parameters than the other days (black dots). Diurnal variations for the 30 March event (red dots) are particularly large, indicating the relevance of strong solar radiation to the nucleation events. Note that air temperature in the $30 \mathrm{March}$ event is lower than the other events because it is the earliest that was observed during the field campaign. The above conditions are common during the winter monsoon when a continental high pressure splits from the main Mongolian high and moves from eastern China toward the Pacific. Such a setting can be manifested with the backward trajectory anal- ysis in Fig. 3 for the 30 March event. One can see that the air mass is of continental origin but with maritime modification over the East China Sea before reaching the Shiman site on Taiwan. The Shimen site is located at the top of a small cliff $78 \mathrm{~m}$ in height and about $100 \mathrm{~m}$ distance from the open ocean that it faces. As the surrounding area is only sparsely populated, the only known source of local pollution is automobiles on a provincial coastal highway underneath the cliff. For the event shown in Fig. 1, the winds were prevailing northeasterly blowing onto the shore, so the chance of them containing fresh anthropogenic emissions should be low. One cannot completely rule out the occasional passage of emission plumes from nearby ships or automobiles. Yet, such an ANC spikes phenomenon has also been observed in other relatively remote areas (e.g. O'Dowd et al., 1999; Coe et al., 2000; Guo et al., 2008) distant from human influence. Therefore, looking into other possible mechanisms that may be responsible for the ANC spikes is worthwhile. Note that the time resolution in Fig. 1 is relatively coarse, and the spikes feature can be much finer as shown in some of these measurement studies.

Earlier postulations of the causes for small particle production include the shattering of salt formed by the rapid evaporation of cloud drops (e.g., Dessens, 1949; Twomey and McMaster, 1955; Radke and Hegg, 1972), but Mitra et al. (1992) disproved this mechanism with wind tunnel experiments. A more plausible cause for generating such nucleation-mode aerosols is homogeneous nucleation from the gas phase. Traditionally, homogeneous nucleation of atmospheric particles is thought to occur via the $\mathrm{H}_{2} \mathrm{O}-\mathrm{H}_{2} \mathrm{SO}_{4}$ binary interaction (Nair and Vohra, 1975; Yue and Hamill, 1979). Nucleation enhancement is possible with the presence of an additional gas such as ammonia (Coffman and Hegg, 1995; Yu, 2006a), volatile organic compounds (O'Dowd et al., 1998), and aromatic acids (Zhang et al., 2004). Such processes are called 

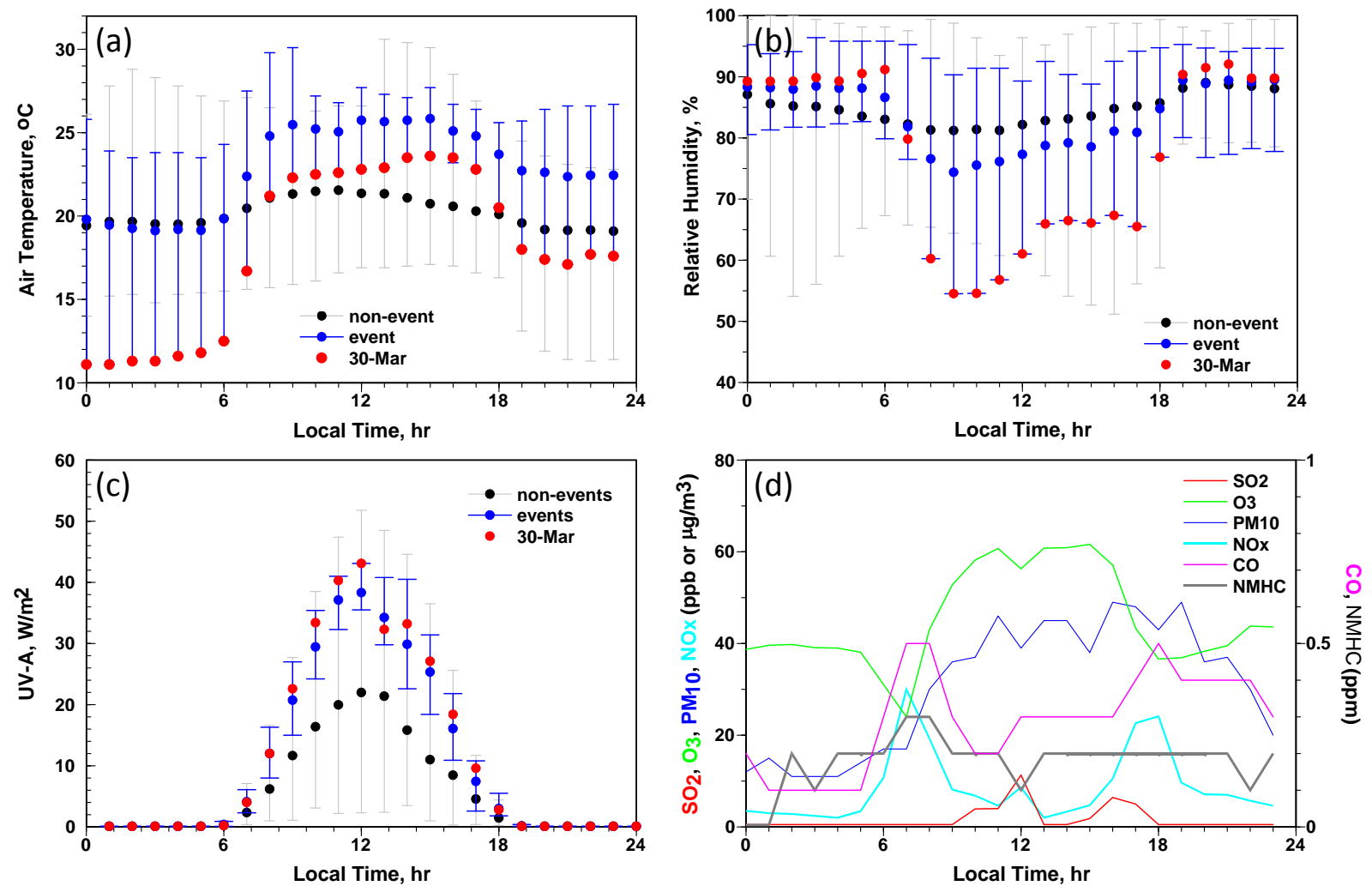

Fig. 2. Diurnal variations of (a) air temperature, (b) relative humidity, (c) UV-A radiation, and (d) concentration of trace chemicals in air. The first 3 panels show averages and spreads for all non-nucleation (black dots) and nucleation (blue dots) events, as well as values for the 30 March event (red dots). Panel (d) shows only the 30 March event.

ternary nucleation. Other nucleation mechanisms are also possible, such as ion enhanced nucleation (Yu, 2006b), but are irrelevant to this study.

According to the classical nucleation theory, the main conditions favorable for binary or ternary homogeneous nucleation are high water vapor saturation ratio $S_{\mathrm{w}}$ (relative humidity) and sulfuric acid vapor saturation ratio $S_{\text {a }}$ (relative acidity), as well as low temperatures. Defined as the ambient vapor pressure divided by the saturation vapor pressure, the saturation ratio may be elevated by either an increase in vapor concentration or by lowering the temperature, thus the saturation vapor pressure. The increase in water vapor concentration usually involves evaporation from the Earth's surface or airborne raindrops. The increase in sulfuric acid concentration, on the other hand, usually requires strong photochemical production which, in turn, demands high concentrations of precursor gas (e.g. $\mathrm{SO}_{2}$ ) and high actinic flux to generate $\mathrm{OH}$ radicals for the reaction to occur. For the sulfuric acid to accumulate in the air, the concentration of existing aerosols, which tend aerolols to consume the acid vapor needed for nucleation, needs to be low (Shaw, 1989; Petters et al., 2006).

A few physical conditions (e.g. the lowering of temperature) favorable to aerosol particle nucleation have also been investigated. The most common way to cause a fast cooling is adiabatic expansion during ascending motion. Easter and Peters (1994) and Nilsson et al. (2001) suggested that turbulence in a well-mixed boundary layer may cause temperature fluctuations and induce new particle formation. Nilsson et al., (2000) also indicated that the upward motion of atmospheric waves could enhance aerosol nucleation. Another way of causing cooling is mixing. Bigg (1997) hypothesized that sudden mixing caused by the breaking of Kelvin-Helmholtz waves may induce strong aerosol nucleation. Similar mechanisms including turbulence mixing have also been investigated by Lesniewski and Friedlander (1995), Nilsson and Kulmala (1998), Khosrawi and Konopka (2003) and Wehner et al. (2010). Cooling due to long-wave radiation is usually too slow to cause strong nucleation.

A combination of some of the above factors is even more sufficient, if not necessary, for aerosol nucleation. Perry and Hobbs (1994) proposed that convective clouds bring up $\mathrm{SO}_{2}$ (precursor of sulfuric acid) by cloud venting and remove a large portion of the existing aerosols by cloud and precipitation scavenging. High relative humidity and reflected sunlight near the clouds together form a favorable nurturing environment for new particles. However, the mechanisms mentioned above, acting individually or in combination, seem to be insufficient in explaining the occurrence of ANC spikes. 


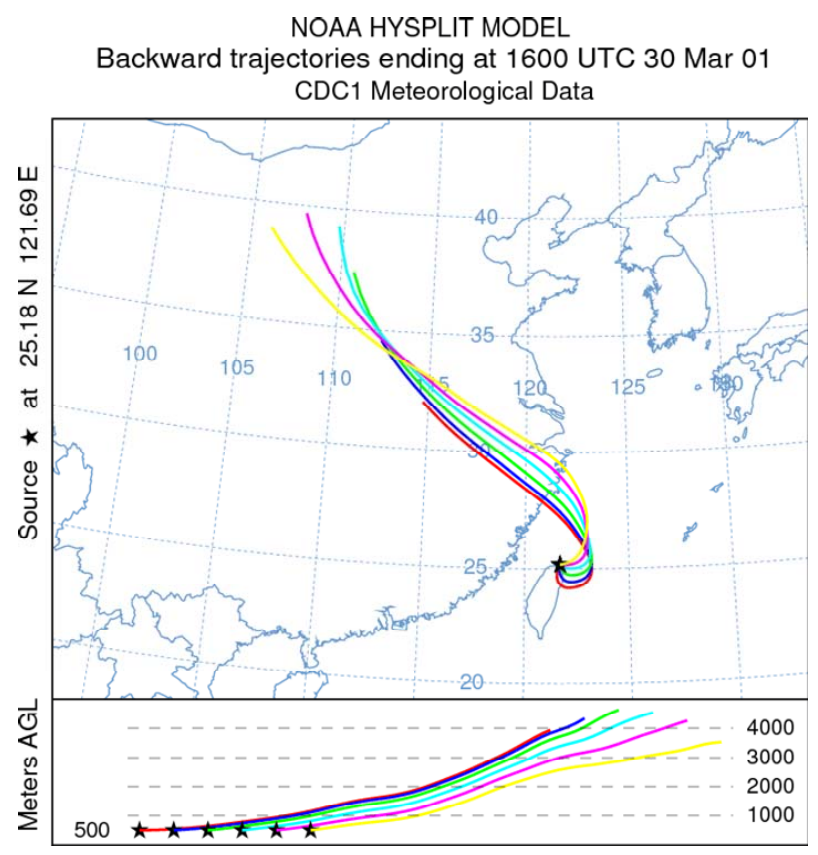

Fig. 3. Backward trajectory analysis generated from the NOAA HYSPLIT model. The starting time of each trajectory is $4 \mathrm{~h}$ apart, from 00:00 (yellow curve) to 24:00 (red curve) local time on 30 March 2001.

A straightforward photochemical mechanism, as simulated by previously mentioned aerosol models, occurs in the diurnal time scale corresponding to the variation in solar radiation. Other effects that occur in a much shorter time scale are necessary to explain the spike phenomenon. One such candidate is the blocking of actinic flux by reoccurring scattered clouds, such as stratocumuli. This effect is one of the main themes of this study. Mixing induced cooling is not likely the mechanism for PBL spikes as it requires the involved air parcels to have distinctly different potential temperatures and the mixing occurs with strong fluctuations, which is apparently not the case under the synoptic conditions for the event in Fig. 1. On the other hand, cooling induced by turbulence does have a time scale similar to the observed ANC spikes and this phenomenon is very common in the PBL. In addition, as will be demonstrated later, turbulence motion has an additional effect of enhancing sulfuric acid vapor concentration.

This study investigates the possible role of cloud shadowing and turbulence motion in ANC spike generation shown in Fig. 1. As the phenomena that we intend to examine occur at rather fine spatial and temporal scales, they cannot be handled easily with typical Eularian models. The Largangian parcel model is quite suitable for our study because it allows finer details in aerosol microphysics and its dynamics can be prescribed to fit our purpose. In the following, we present several simulations from the aerosol parcel model and discuss possible mechanisms for ANC spikes.

\section{Aerosol parcel model and simulation setup}

The Lagrangian parcel model applied for this study was modified from the multi-component particle model of Chen and Lamb (1994, 1999), which allows simultaneous and independent changes in various physical and chemical properties of aerosol and cloud particles. For this study, two bincomponents - water mass $m_{\mathrm{w}}$ and sulfate mass $m_{\mathrm{s}}-$ are used for the particle framework, with 45 and 65 bins each assigned for $m_{\mathrm{w}}$ and $m_{\mathrm{s}}$. The lower limits of the largest bin for $m_{\mathrm{w}}$ and $m_{\mathrm{s}}$ are $2.3 \times 10^{-9} \mathrm{~mol}$ and $5.6 \times 10^{-10} \mathrm{~mol}$ (roughly equivalent to $10 \mu \mathrm{m}$ radius), respectively; whereas the upper limit of the lowest bin for $m_{\mathrm{w}}$ and $m_{\mathrm{s}}$ are $1 \times 10^{-23} \mathrm{~mol}$ and $3 \times 10^{-22} \mathrm{~mol}$ (roughly equivalent to $1 \mathrm{~nm}$ radius), respectively. A bin-sizing factor of 2 and 1.5, respectively, is applied to successively smaller bin limits, except for the first and last bins having relaxed upper and lower boundaries, respectively, to cover extreme conditions. A methodof-moments type scheme is used to conserve mass and the number of particles, as well as reduce numerical diffusion, for their redistribution within the particle framework due to various growth mechanisms.

The growth mechanisms considered include binary nucleation and condensation growth from water and sulfuric acid vapors, as well as Brownian coagulation between particles. For the binary nucleation, we applied the classical theory for the water-sulfuric acid system with Zeldovich factor modification (cf. Doyle, 1961; Seinfeld and Pandis, 2006, pp. 514 520 ) but ignored the hydrate formation effect.

Condensation growth from both water vapor and sulfuric acid follows the Maxwellian two-stream theory with consideration of the curvature and solute effects on the particle surface vapor pressures, as well as the surface gas-kinetic effect (cf. Pruppacher and Klett, 1997). Coagulation between particles is calculated using the Brownian collision kernel from Fuchs (1964) and a unity coagulation efficiency. Cloud formation may occur in some of the simulations. For this, the model does consider aerosol activation into cloud drops according to the Köhler theory. The condensation growth of cloud drops are treated the same as for the aerosol particles. Our model also considers the collision-coalescence between cloud drops, as well as interstitial (un-activated) aerosol collection by cloud drops. To focus on microphysical aerosol processes, a simple treatment is applied to the gas-phase production of sulfuric acid vapor. This production is assumed to come solely from $\mathrm{SO}_{2}$ oxidation by $\mathrm{OH}$, with a clear-sky reaction rate parameterized as a sinusoidal function of time to mimic the diurnal change in actinic flux and $\mathrm{OH}$ concentration according to an offline calculation from a photochemical model initialized with typical trace gas concentrations for the Shimen area. It is possible that other condensable gases, such as ammonia or organic vapors, may involve in the nucleation and condensation growth processes. Note that the ability of organic compounds to form new particles in the atmosphere is a rather controversial issue (Kanakidou et 
al., 2005), and the species that involved (e.g. oxygenated organics) are poorly known, especially for the area studied here. Such nucleation by organic vapors could also be suppressed easily by growth onto existing particles. There are also indications that atmospheric organics might not be very copious in our case. The non-methane hydrocarbon concentration measured at a near-by air pollution monitoring station was around $0.2 \mathrm{ppm}$ for this and other similar events. Wang et al. (2004) reported that the average organic carbon content in PM10 measured during this field experiment was less than $10 \%$, relatively low compared with urban situations or over large forest regions. In any case, organics and other compounds might be involved in particle growth but are not likely to dominate the nucleation process. As will be shown later, binary nucleation and condensation growth in the water-sulfuric acid system is sufficient to produce the observed phenomenon. So, ignoring organics and other compounds should not affect the general conclusion of this study.

The key parameters needed for the above calculations include the saturation vapor pressure of sulfuric acid from Jaecker-Voirol et al. (1990), saturation vapor pressure for water from Tabata (1973), solution water activity and sulfuric acid activity from Jaecker-Voirol and Mirable (1989), and the solution density data from the CRC Handbook for Physics and Chemistry. For the surface tension of sulfuric acid solution, we fitted the experimental data of Morgan et al. (1916) as a function of concentration and temperature, and for the latter, the van der Walls (1894) formulation was applied. Note that large uncertainties exist in the calculation of nucleation rate from the classical theory, partly due to the ambiguity in these thermodynamic parameters which the nucleation rate is very sensitive to. Also note that, as pointed out by Korhonen et al. (1999), while some studies showed that predictions of binary nucleation from $\mathrm{H}_{2} \mathrm{SO}_{4}$ and $\mathrm{H}_{2} \mathrm{O}$ are consistent with the measured new particle formation, others indicated that such binary nucleation may be too weak to explain the observed particle production, and the latter seems to be particularly true for the marine boundary layer or continental sites (conditions similar to that for Fig. 1). Yet, our calculation seems to give reasonable results. One possible reason for us to obtain sufficiently high nucleation rates is that we considered the size effect on surface tension. Tolman (1949) pointed out that surface tension may be significantly less than its bulk value when the particle is small, especially for the nucleation embryos and nucleation-mode particles. For example, the curvature effect causes the surface tension of a drop with radii of 1 and $3 \mathrm{~nm}$ to reduce by $9 \%$ and $24 \%$, respectively. This effect has strong influence on the nucleation and condensation processes but is not considered in most aerosol models. In our model this effect has been included according to the treatment in Chen (1994). This extra factor enhances the nucleation rate by about two orders of magnitude, similar to what one would get by considering the hydrate effect. Because of several self-limiting factors, such as the depletion of vapors by the growth of newly formed particles or the coagulation to existing large particles, the overall number of new particle production actually does not vary too strongly with the nucleation rate. We performed a sensitivity test by artificially modifying the nucleation rates by a factor of 10 and 0.1 , the resulting variation in total aerosol number concentrations is within a factor of 2 , which is small in comparison to the two orders of magnitude change in nucleation rates. The variation in $D>10$ particles larger than $10 \mathrm{~nm}$ in diameter (the detection limit of our SMPS) is even less significant. Therefore, inaccuracy in the nucleation rate does not lead to an equally large error in the total production of new aerosols.

Several simulations are designed to examine the two effects relevant to the ANC spikes phenomenon. The cloud shadow effect is considered by imposing a reduction of the transmitted actinic flux (thus the production of sulfuric acid vapor) for the scattered stratocumulus clouds (Sc) situation. The turbulence cooling effect is considered by giving the air parcel a large-eddy type of motion. Both the stratocumuli and turbulence eddies are quite common to the area of study during spring when the PBL is dominated by the continental cold-air outflow. The stratocumuli formation near the top of the PBL is associated with the mechanically forced turbulence eddy in the PBL, where clouds form in the ascending region and dissipate during descends. Air parcels in such a turbulent environment tend to have wave-like motions as demonstrated by the trajectory analysis of Feingold et al. (1998). Therefore, the turbulence air parcel is assumed to move up and down adiabatically following a sinusoidal trajectory. According to the results of Feingold et al. (1998), we selected a cycling period of $30 \mathrm{~min}$ and semi-amplitude of $500 \mathrm{~m}$ for our main simulations, but other values were also tested. The same sinusoidal function was also used to calculate the attenuation of actinic flux below the stratocumuli, such that the actinic flux oscillates from a specified minimum value (at the center of cloud shadow) to a clear-sky value. Also simulated for comparison was the influence of stratus clouds (St) which are assumed to distribute uniformly in space and time.

The presence of existing aerosol particles as they may consume sulfuric acid vapor and hinder the nucleation process needs to be considered also in (or for) the simulations. The initial size distribution is assumed to be a bi-modal lognormal function (cf. Whitby, 1978), parameterized according to the mean size distribution measured at Shimen during March and April of 2003. Its total number concentration of $2690 \mathrm{~cm}^{-3}$ represents a relatively clean rural condition. For comparison purposes, we also applied an average aerosol size distribution measured in the city of Taipei (located $30 \mathrm{~km}$ south of Shimen), with total number concentration of $15080 \mathrm{~cm}^{-3}$ representing urban conditions.

For the simulation of either the Sc or St cloud-shadow effects, the air temperature and relative humidity of the air parcel were fixed at $20^{\circ} \mathrm{C}$ and $75 \%$, respectively, which are typical ambient conditions at sunrise for the situation studied 

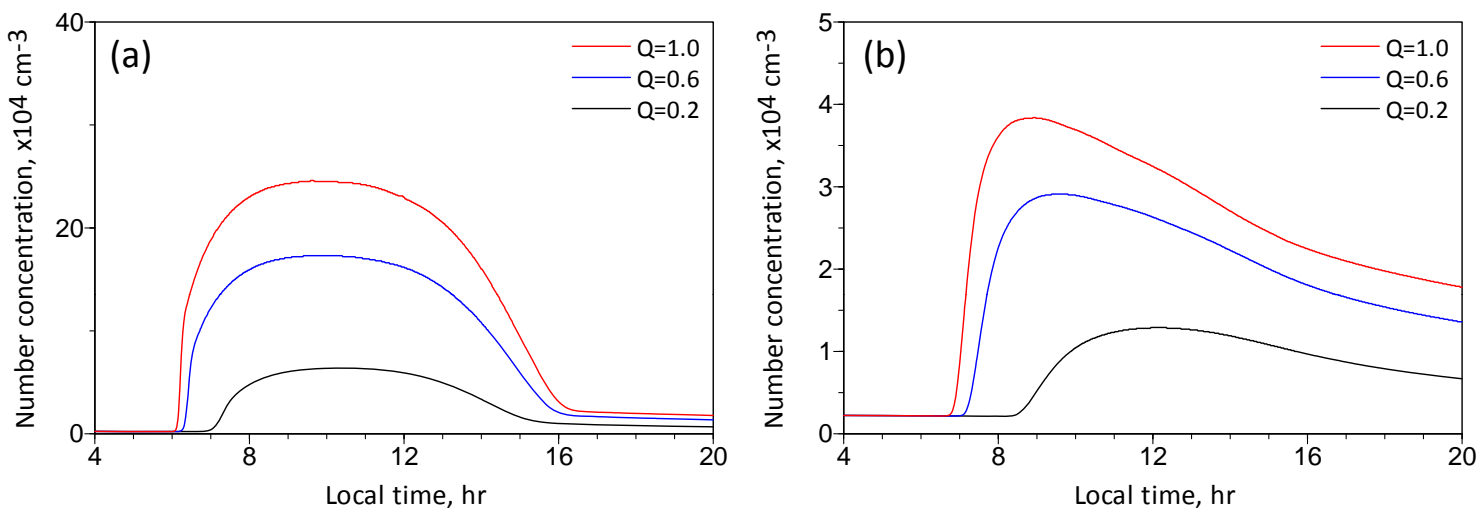

Fig. 4. Simulated diurnal evolution of aerosol number concentration for the conditions of Shimen with different actinic flux transmission ratios. (a) All particles ( $D$-all); (b) Particles with diameter greater than $10 \mathrm{~nm}(D>10)$.

here. Although in reality the temperature and relative humidity of the PBL air do vary with time due to solar heating and other meteorological factors, they are fixed so that a direct comparison can be made with the turbulence simulations for which the air parcel is assumed to proceed adiabatically. The effect of varying ambient conditions will be discussed. The simulation setup for all cases is summarized in Table 1.

\section{Simulation results}

Let us first examine a simpler cloud shadow effect case - the uniform St clouds - for the conditions at Shimen. As shown in Fig. 4a, the aerosol number concentration increases drastically after sunrise due to sulfate photochemical production. Under clear skies, the number of aerosols may increase by two orders of magnitude. When the actinic flux is attenuated by uniform clouds (represented by a transmission ratio $Q$ ), the burst of aerosols is reduced in magnitude as well as delayed in time. Note that, unlike Fig. 4a which includes aerosol particles of all sizes (denoted as $D$-all), the measurements with the TSI SMPS-3934 for this study covered only particles from about 10 to $500 \mathrm{~nm}$ in diameter (with 102 intervals). To give a fair comparison with observations, we show in Fig. 4b only particles with diameters larger than $10 \mathrm{~nm}$ (denoted as $D>10$ ). Here, the nucleation burst is still evident and the maximum number concentration is now of a similar magnitude as the observation that shown in Fig. 1a. The large decrease in particle number for $D>10$ indicates that the fresh particles growth by condensation is slow, and the fresh particles collection by the larger pre-existing particles is strong. Figure 5 shows the simulated evolution of aerosol size distribution (ASD) for the $Q=1$ case. One can see the development of nucleation mode particles after sunrise. The modal size increased quickly from $10 \mathrm{~nm}$ to over $20 \mathrm{~nm}$ during the nucleation burst stage, then gradually reached $30 \mathrm{~nm}$ and remained there in the afternoon, similar to that shown in Fig. 1b. Comparing Figs. 4 b and 5 with Fig. 1, one can see that the simulated nucleation burst started one to two hours earlier than observed except when the photochemical production was very weak $(Q=0.2)$, which is not likely in the real case. Yet, when the observed temperature and relative humidity variation (instead of at fixed values) were applied in the simulations, the timing of the nucleation burst was delayed mainly because of lowered humidity and becomes more compatible with Fig. 1a.

Similar to other aerosol model results, the nucleation burst shown in Figs. 4 and 5 lacks the spikes feature shown in Fig. 1. Additional mechanisms must exist to produce such spikes. We next examine whether intermittent cloud shadows due to re-occurring stratocumulus may be one of the causes. Figure 6 shows the simulations with imposed sinusoidal attenuation of the actinic flux due to stratocumulus, with the transmission ratio vary periodically from unity to a minimum value denoted by $Q$. Note that the curves for $Q=1$ represent a total transmission thus are exactly the same as those for the clear sky condition in Fig. 4. From Fig. 6a, one can see that new particles are generated during cloud breaks when there is sufficient sulfuric acid vapor production by photochemistry. Under cloud shadows, the particle number actually decreased rapidly because of reduced photochemistry and a strong coagulation of the newly formed particles with the existing ones. Such a sharp fluctuation repeats itself for each cloud cycle when there is sun light. The particle reduction during the cloud shadow period actually helps the nucleation later because the existing aerosols become fewer, thus are less capable of consuming sulfuric acid vapor by condensation. This effect can be seen clearly from the higher maximum number concentrations during cloud breaks than that for the all clear sky condition $(Q=1)$. The fluctuation of particle numbers for $D>10$ becomes much less significant although still visible (Fig. 6b).

Cloud shadow effect seems to be able to cause fluctuations in particle nucleation. But the amplitudes of fluctuation for $D>10$ are much less striking than the observed spikes shown in Fig. 1a. Apparently a different mechanism 
Table 1. Summary of the simulation cases and parameters used. All "turbulence" cases have a mid-level relative humidity of $80 \%$ except the one named RH75 used a value of $75 \%$.

\begin{tabular}{|c|c|c|c|c|}
\hline Case name & Actinic flux & Vertical motion period & Vertical motion amplitude & Figure number \\
\hline stratiform & uniform & - & - & 4,11 \\
\hline stratocumulus & $\begin{array}{c}\text { sinusoidal } \\
(\text { period } 1800 \mathrm{~s})\end{array}$ & - & - & 6 \\
\hline turbulence & uniform & & & \\
\hline $0.5 \mathrm{~h}$ (reference case) & & $1800 \mathrm{~s}$ & $500 \mathrm{~m}$ & 7,11 \\
\hline $1 \mathrm{~h}$ & & $3600 \mathrm{~s}$ & $500 \mathrm{~m}$ & 11 \\
\hline $0.25 \mathrm{~h}$ & & $900 \mathrm{~s}$ & $500 \mathrm{~m}$ & 11 \\
\hline RH75\% & & $1800 \mathrm{~s}$ & $500 \mathrm{~m}$ & 11 \\
\hline Half amplitude & & $1800 \mathrm{~s}$ & $250 \mathrm{~m}$ & 11 \\
\hline Varying amplitude & & $1800 \mathrm{~s}$ & $\begin{array}{c}0 \sim 500 \mathrm{~m} \\
\text { (sinusoidal; period } 700 \mathrm{~s} \text { ) }\end{array}$ & 12 \\
\hline
\end{tabular}

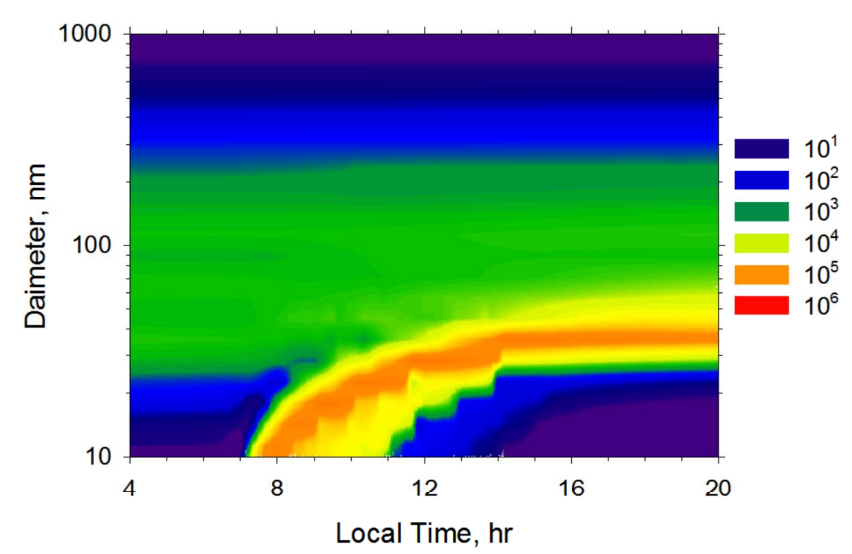

Fig. 5. Simulated evolution of aerosol size distribution corresponding to the St scenario in Fig. 4. The color bars show the particle number density $(\mathrm{d} N / \mathrm{d} \log D)$ in $\mathrm{cm}^{-3}$.

is required to explain the observation. As will be shown next, the mechanism of turbulence-induced nucleation is quite capable of causing stronger fluctuations in nucleation.

To simulate the effect of large eddy turbulence, the air parcel is assumed to rise and sink adiabatically following a sinusoidal vertical path. In the rising part of the eddy, the expanding air cools down rapidly and the lowering temperature causes an increase in both $S_{\mathrm{w}}$ and $S_{\mathrm{a}}$, which leads to enhanced nucleation. Clouds often form at the top of the large eddies in the PBL. For the results shown below, the $S_{\mathrm{w}}$ of air parcel varies from $64 \%$ at the surface to about $80 \%$ at mid-level and reaches over $100 \%$ near the top where clouds are formed. Other conditions are the same as those for previous simulations. Reductions in actinic flux similar to those specified for the St simulations in Fig. 4 are also imposed. In Fig. 7a, one can see the large eddy motions caused a pulsating production of aerosols similar to that shown in Fig. 6a but with significantly stronger amplitudes. For $D>10$ (Fig. 7b), the fluctuation is still obvious and much more significant than that in Fig. 6b, except for $Q<0.2$ for which the variation becomes insignificant. When $Q=1$, both the peak number concentration and the spike features are quite similar to those shown in Fig. 1a. Detailed evolution of ASD for this simulation is shown in Fig. 8. One can see that the nucleation burst pattern is generally similar to that in Fig. 5 but with additional fine features resembling the observed strips pattern in Fig. 1b. Note that the results in Figs. 7 and 8 are along the parcel trajectory and thus cannot be directly compared with the surface measurement in Fig. 1a. Discussions on this discrepancy will be given later.

The cause of the pulsating particle bursts is not just a simple effect of cooling-enhanced nucleation. In fact, one may have noticed some irregularities in the evolution of particle number concentration in Fig. 7 as compared with Fig. 6. The details can be revealed by zooming up a couple of the cycles. As the behavior of each cycle is similar, we will focus on the two cycles occurring between 11 a.m. and noon. In Fig. 9a, one can find two peaks in the number concentration in each cycle in contrast to the single peak in Fig. 6 . The situation for $D>10$ is even more complicated. To understand this result we need to examine the parameters most critical to the binary nucleation - the relative humidity $S_{\mathrm{w}}$ and relative acidity $S_{\mathrm{a}}$ of the air parcel.

The ups and downs of $S_{\mathrm{w}}$ shown in Fig. 10a basically reflect the imposed periodical variation in vertical motion. So, $S_{\mathrm{w}}$ increases in the updraft due to expansion cooling and decreases in the downdraft due to compression warming. The expansion cooling should in principle also cause an increase in $S_{\mathrm{a}}$, provided that the sulfuric acid vapor mixing ratio is kept constant. Yet, the simulation shows that the variation in $S_{\mathrm{a}}$ is out of phase with $S_{\mathrm{w}}$, indicating an additional source or sink for sulfuric acid vapor. The formation of clouds, as 

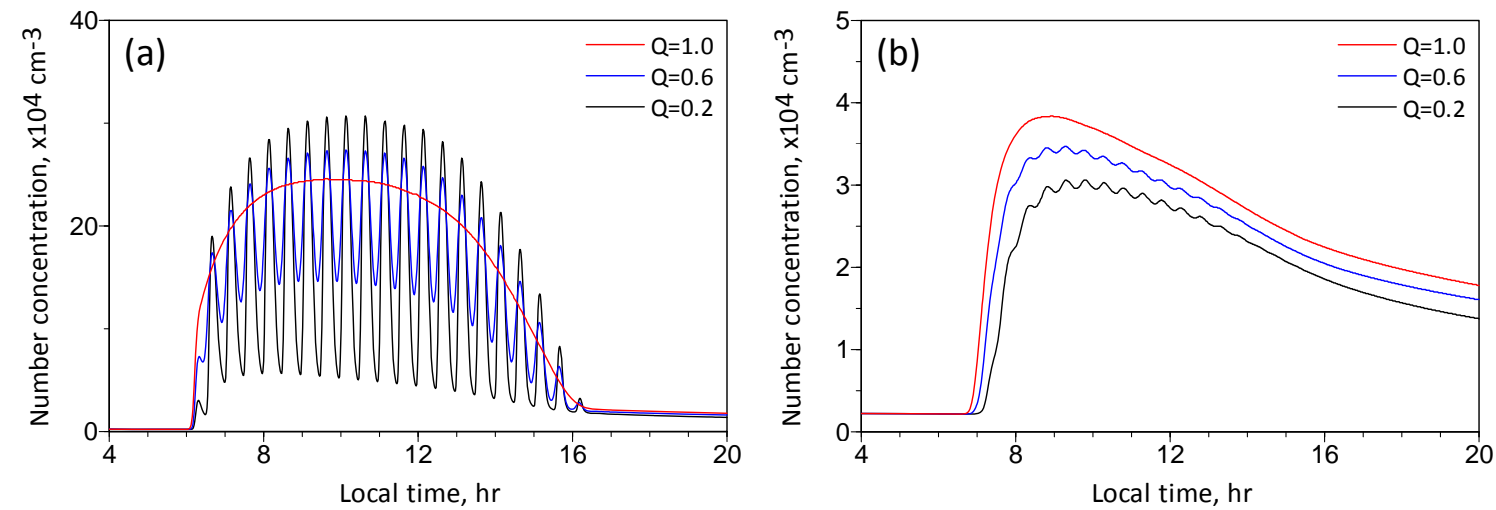

Fig. 6. Same as Fig. 4, but with the influence of stratocumulus cloud shadows.
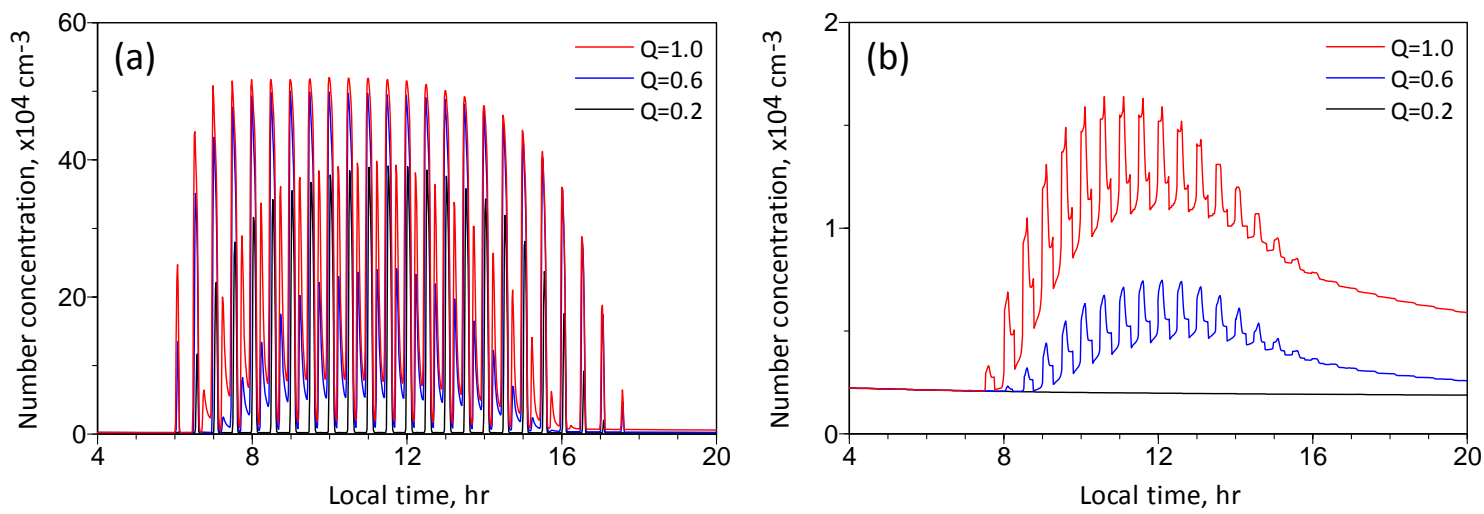

Fig. 7. Simulations of new particle production in air parcel moving in the form of large eddy circulation within the atmospheric boundary layer. The amplitude and period of the large eddy are set as $500 \mathrm{~m}$ and $30 \mathrm{~min}$, respectively. The left panel shows the variation of $D$-all, and the right panel is for $D>10$.

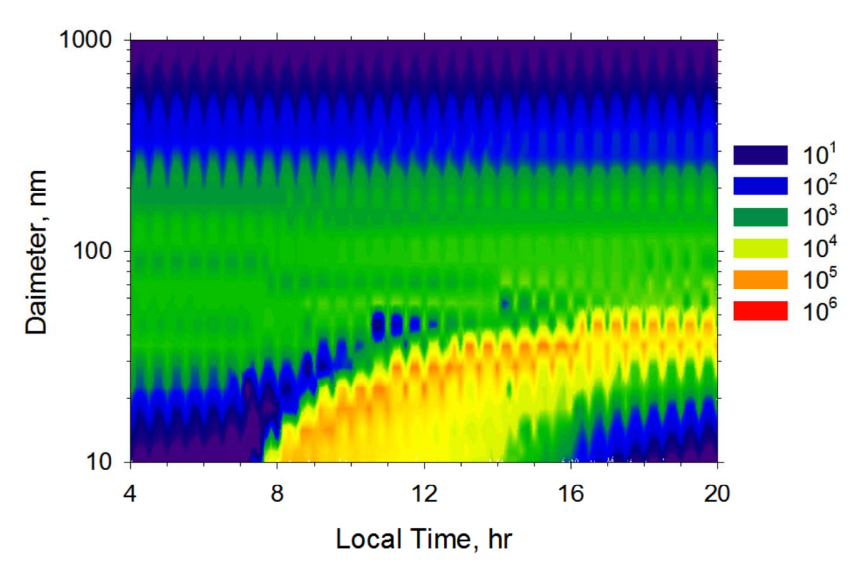

Fig. 8. Same as Fig. 5, but for the turbulence eddy scenario corresponding to Fig. 7.

indicated by the development of supersaturation $\left(S_{\mathrm{w}}>1\right)$, at the tops of the circulation play an important role here. In fact, $S_{\mathrm{a}}$ is the lowest when the air parcel is inside the cloud (the reason for which will be explained later). It then in- creases rapidly in the downdraft after the clouds have dissipated. Since the photochemical production of sulfuric acid vapor varies only slowly during the hour (dashed curve in Fig. 10b), the increase in $S_{\mathrm{a}}$ in the downdraft must be due to slower sulfuric acid vapor condensation (dotted curve in Fig. 10b). This retarded condensation is mainly a consequence of the drastic reduction in existing particles in the clouds. This reduction has two causes. First, Brownian collection is greatly enhanced due to the large size of the cloud drops, and should be the main reason for the disappearance of interstitial aerosols. Second, the growth of cloud drops by water vapor condensation considerably reduces the Henry's law surface pressure of sulfuric acid vapor, and this leads to a thermodynamic imbalance between the cloud drops and interstitial particles whose surface vapor pressures are elevated due to the large curvature effect. Therefore, the cloud drops can uptake sulfuric acid in the expense of evaporating interstitial aerosols, and some of the smaller ones may evaporate completely if they are not already collected by the cloud drops. Furthermore, the size reduction of interstitial aerosols by evaporation also enhanced their Brownian motion and 

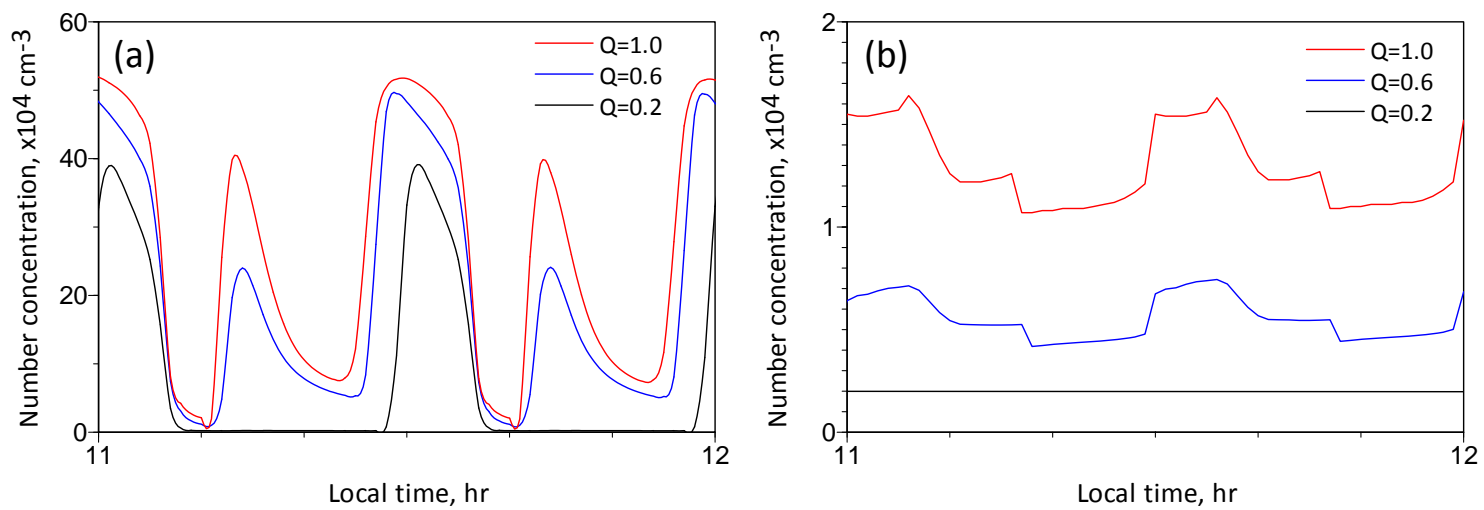

Fig. 9. Same as Fig. 7, but zoom up for the period between 11 a.m. and noon.
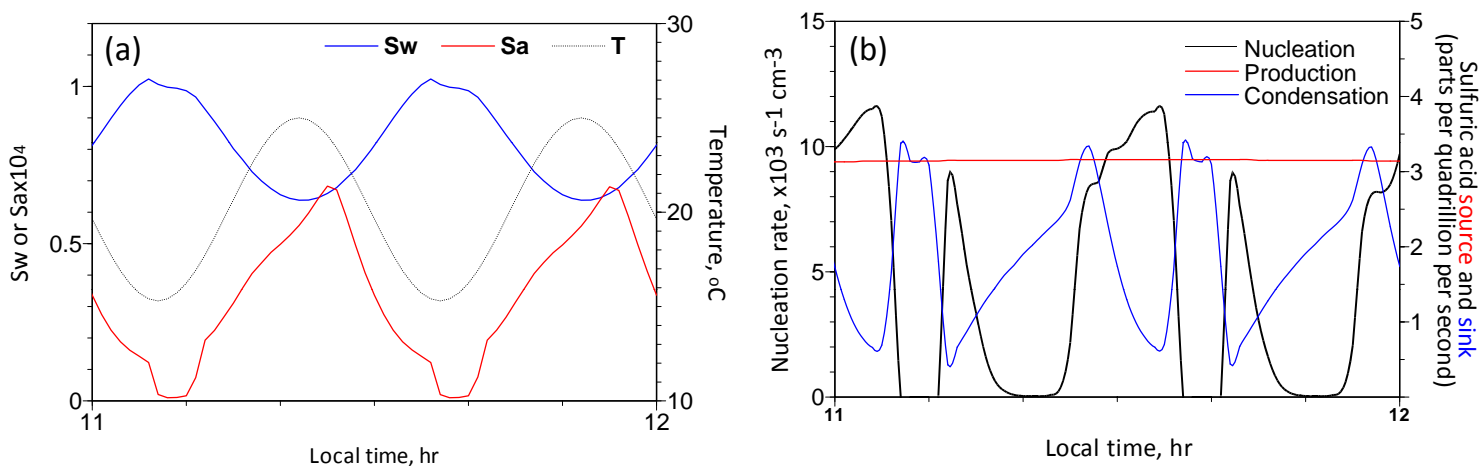

Fig. 10. Evolution of (a) relative humidity $S_{\mathrm{W}}$, relative acidity $S_{\mathrm{a}}\left(\mathrm{x} 10^{4}\right)$ and temperature $T$; (b) nucleation rate (in per unit volume and unit time; black curve), as well as rates (in parts per quadrillion by volume per second) of photochemical production (red curve) and condensation (blue curve) of sulfuric acid vapor for the case of $Q=1$ in Fig. 9. Time length shown is the same as in Fig. 9.

thus the chance of being collected by cloud drops or larger aerosols. So, in the downdraft, after the clouds have dissipated, the number of aerosol particles for the sulfuric acid vapor to condense on is very low. This leads to a buildup of $S_{\mathrm{a}}$ (Fig. 10a) which is favorable to nucleation (Fig. 10b). Hence, the particle number shoots up at about 11:11 (and 11:41) as shown in Fig. 9. A second mechanism which leads to a slower sulfuric acid vapor condensation in the downdraft is the drying of air parcels (i.e. lowing $S_{\mathrm{w}}$ ) as a result of adiabatic warming. The drying effect causes the particles to lose water and their dissolved sulfuric acid becomes more concentrated. The reduction in size and the elevation of solute concentration both lead to a slower sulfuric acid vapor condensation. In the later part of the downdraft, the nucleation becomes very weak due to new particle formation and the lowering of $S_{\mathrm{w}}$, even though $S_{\mathrm{a}}$ at the time is still increasing. So, at about 11:23, the production by nucleation is not enough to compensate for the loss due to collision or complete evaporation and the particle number reaches its secondary minimum.
A second nucleation spike (of the same cycle) occurs in the updraft. It starts at about 11:24 when $S_{\mathrm{w}}$ begins to increase due to adiabatic cooling and while $S_{\mathrm{a}}$ is still building up (because the photochemical production of sulfuric acid vapor is still stronger than the loss by condensation). This updraft-induced spike is stronger than that in the downdraft in both magnitude and duration. It ends when the formation of new particles is so overwhelming that the sulfuric acid vapor condensation on the particles significantly exceeds the photochemical production. In addition, the swelling (and dilution) of existing particles due to increasing relative humidity also enhances condensation. The complete termination of nucleation (at around 11:37) happens when the air parcel reaches the condensation level, as the growing cloud drops quickly absorb sulfuric acid vapor and cause $S_{\mathrm{a}}$ to decrease to its lowest level.

The similarity between the $Q=1$ result in Fig. $7 \mathrm{~b}$ and the observed result in Fig. 1a may give us a false impression that the answer has been found. However, there is a problem comparing Fig. 7b directly with Fig. 1a, because the former was calculated following the undulating air parcel and thus cannot represent the situation at the surface. If only the surface 


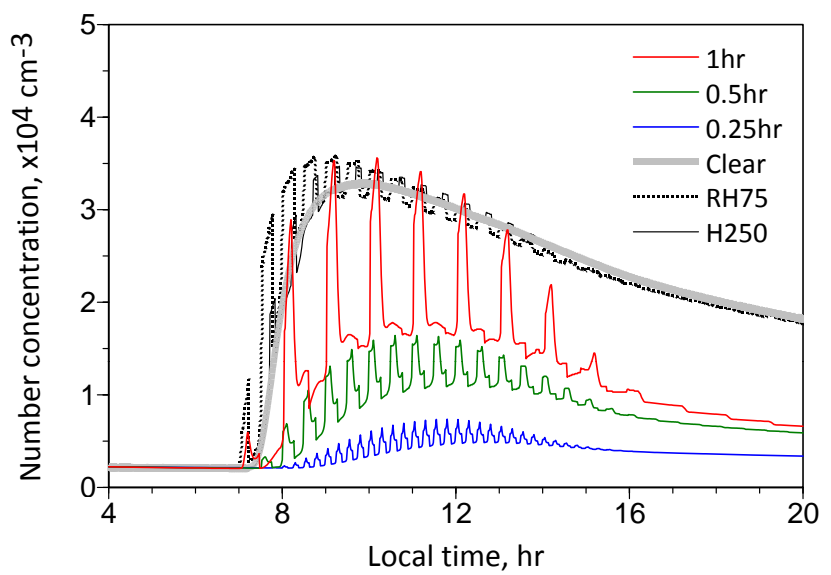

Fig. 11. Evolution of $D>10$ aerosol number concentrations under various scenarios of turbulence eddy. The green curve (cycle period $0.5 \mathrm{~h}$ ) is the same as the $Q=1$ curve in Fig. $7 \mathrm{~b}$, and is called the reference run. The thick-grey curve is the same as the $Q=1$ curve in Fig. 4b, representing the clear sky situation without turbulence eddy. The red curve and the blue curve applied the same conditions as the reference run except for the cycling periods of $1 \mathrm{~h}$ and $0.25 \mathrm{~h}$, respectively. The dotted curve (RH75) differs from the reference run in its lower (by $5 \%$ ) initial relative humidity; while the thinsolid curve (H250) applied a vertical amplitude that is one half of the reference run (a half-height of $250 \mathrm{~m}$ ).

values were plotted (i.e., connecting the lowest point of each cycle), one would see only a simple nucleation burst without all the spikes (similar to the $Q=1$ curve in Fig. 4b). But this discrepancy does not necessarily invalidate the turbulenceinduced nucleation mechanism. For the results in Fig. 7, the physical parameters (e.g., frequency or amplitude) of the turbulence eddies were fixed, yet in reality they vary significantly with time and space. We will next demonstrate that such variations may be enough to cause the spikes in particle number concentration at the surface.

Figure 11 shows the evolution of $D>10$ particles for a few additional simulations of different turbulence eddies. Two earlier results are also included for comparison: (1) the thick-grey curve labeled "Clear" is the clear-sky, no turbulence case, and is the same as the $Q=1$ curve in Fig. 4b; (2) the green curve labeled " $0.5 \mathrm{~h}$ " (oscillation period of $0.5 \mathrm{~h}$ ) is the reference case of turbulence eddy, and is the same as the $Q=1$ curve in Fig. 7b. Let us first look at two curves which contain some fluctuations but have baselines following close to the "Clear" curve. For these two cases, the same conditions as the " $0.5 \mathrm{~h}$ " case were applied, except that the mid-level relative humidity was lowered by $5 \%$ for the "RH75 \%" (dotted) curve; whereas for the "H250" (thinsolid) curve, the oscillation amplitude was reduced by one half. The reason for these two curves to behave so differently from their reference case (green curve) is the absence of cloud formation due to either not enough moisture (RH75) or not enough vertical lift (H250). Earlier we have shown that

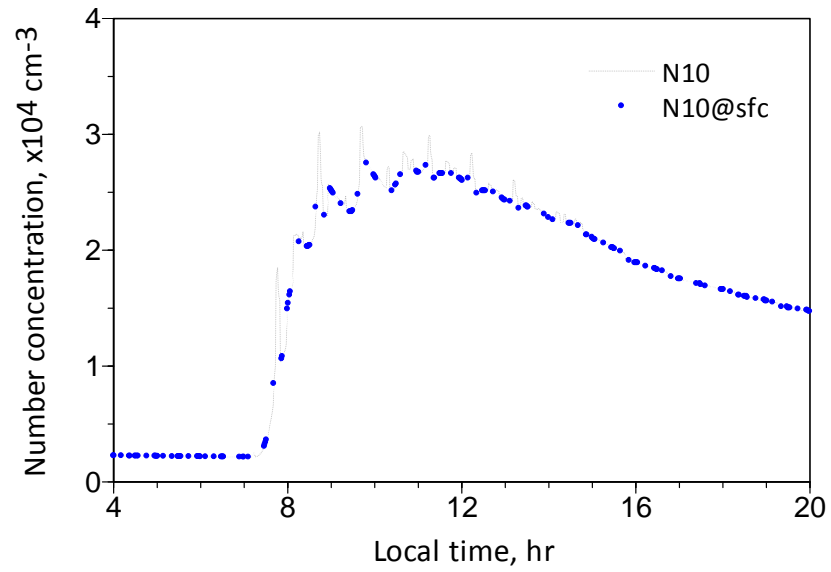

Fig. 12. Same as the reference run (green curve) in Fig. 11 but for turbulence eddies with varying vertical amplitudes. The lightdashed curve is along the parcel trajectory, and the solid dots are near surface values.

clouds can effectively remove the existing particles. Without cloud formation, the near-surface concentration of $D>10$ particles stays not far from that of the clear-sky no-turbulence case. The next two simulations will demonstrate how sensitive the aerosol concentration is to the cloud properties.

The curves labeled " $1 \mathrm{~h}$ " (red) and " $0.25 \mathrm{~h}$ " (blue) differ from the reference case in their doubled and halved oscillation period, respectively. As the amplitude of vertical movement remains unchanged, clouds are formed when the air parcel reaches the top just like in the reference case. The three cases with cloud formations (e.g. the curves labeled " $1 \mathrm{~h}$ ", " $0.5 \mathrm{~h}$ " and $0.25 \mathrm{~h}$ ") not only behave differently from those without cloud formation but also exhibit large discrepancy among themselves. When clouds are present, the fluctuation in particle number is much stronger and the minimum particle number (representing the situation near the surface) is significantly lower, reflecting strong in-cloud processing of existing aerosols as discussed earlier. Such an effect is stronger for shorter oscillation periods for two reasons. First, the time for nucleation to proceed in each cycle is shorter, so the accumulated particle number production is reduced. This time factor also limits the growth of the newly produced particles to $D>10$ sizes. Therefore, the simulation with the shortest oscillation period $(0.25 \mathrm{~h})$ produced the lowest particle number concentration and the weakest fluctuations.

As shown by Feingold et al. (1998) and others, the eddylike movement of air parcels in the PBL often has large variations in amplitude and frequency. So, one can imagine that altering the paths of eddy motions would cause the surface particle number to fluctuate. To demonstrate this, additional simulations were done by applying a sinusoidal variation to the eddy amplitude, so the parcel did not always reach the boundary layer top in each cycle. Figure 12 shows one of the simulations using a period of $700 \mathrm{~s}$ for the variation of 
vertical amplitude from zero to $1 \mathrm{~km}$. One can see that the near-surface (height $<5 \mathrm{~m}$ ) values (highlighted as dots) do fluctuate with time even though there are gaps in the data. Note that the gaps can be filled up with other sets of simulations but this not done here to simplify the presentation.

In either updrafts or downdrafts, the nucleation spikes generally are associated with a low amount of existing aerosol particles at a prior time. This implies that when the amount of existing aerosols is high, such as in an urban environment, nucleation might be prohibited even when there is a strong photochemical production of sulfuric acid (or other condensable vapors that may involve in the nucleation process). To examine this prospect, we performed another set of simulations similar to those shown in Figs. 4-8, but the initial aerosol size distribution was switched to the urban (Taipei) type. None of these simulations produced a noticeable nucleation burst, not to mention spikes, in $D>10$ particles. Only the turbulence eddy case showed significant fluctuations in $D$-all particles (figures not shown). This result also implies that cloud processing becomes quite weak under polluted situations, as the cloud drops become much smaller although more numerous. So, a large amount of existing particles tends to suppress nucleation, as well as prohibiting the nucleated particles to grow to the $D>10$ sizes. Such results are consistent with other studies of nucleation.

\section{Discussion and Conclusion}

This study applied a detailed aerosol model running in the parcel mode to investigate possible causes of the large fluctuations (spikes) in the aerosol number concentration in the planetary boundary layer (PBL) observed during a nucleation burst event. Two mechanisms for such ANC spikes were investigated: (1) cloud shadow effect, and (2) turbulence eddy effect. These re-occurring effects have time scales of a few tens of minutes, roughly the same as that of the observed ANC spikes.

The cloud shadow effect reduces the actinic flux that reaches the PBL, thus reducing photochemical production of sulfuric acid vapor which is essential for binary nucleation to occur. Simulations of this effect do produce large fluctuations in the evolution of total particle concentration. However, for particles with sizes above the instrument detection limit (larger than $10 \mathrm{~nm}$ diameter, denoted as $D>10$ ), the fluctuations are somewhat less obvious than observed. It is possible that the variation in actinic flux assumed in this study is not sharp enough to cause enough fluctuation in particle nucleation.

Mechanically forced large eddy motions in the PBL can cause much stronger fluctuations in $D>10$ particle number concentration along the parcel trajectory, with magnitudes similar to those observed. The nucleation is enhanced mainly in the updraft, where cooling due to adiabatic expansion results in a sharp increase in the water saturation ratio. This updraft-mode nucleation benefits from the reduction in particles during the downdraft stage. Such updraft-mode nucleation has been investigated by Easter and Peters (1994) who concluded that nucleation can be enhanced at higher altitudes in the PBL, and this view is shared by Clarke et al. (1998). However, our results in Fig. 9 show that the fastest increase in aerosol number occurred at lower altitudes before arriving at the mid-level PBL.

Another mode of nucleation may occur in the downdraft, particularly when there is cloud formation at the PBL top. In the downdraft, adiabatic warming may cause the relative humidity and relative acidity to decrease, which is unfavorable for nucleation. But the drying effect also causes the solution in aerosol to become more concentrated and this prohibits sulfuric acid vapor condensation on the existing particles. Such an effect actually causes the relative acidity to increase in the downdraft, thus favoring the nucleation of aerosols. The presence of clouds further enhances the downdraft-mode nucleation because of the collection of interstitial aerosol particles by cloud droplets. Once the cloud dissipates during the descending stage, the amount of existing particles has been significantly reduced so that their ability to consume sulfuric acid vapor is minimized, allowing the relative acidity to accumulate. Because of the higher altitude in which it occurs, this downdraft-mode nucleation may be relevant to the particle nucleation phenomenon observed in the vicinity of marine boundary layer clouds (e.g. Dinger et al., 1970; Hegg et al., 1990; Perry and Hobbs, 1994; Frick and Hoppel, 1993). Furthermore, Clarke et al. (1999) showed that particle production occurred near the edges of evaporating clouds in the marine PBL. They suggested that classical binary nucleation theory may be able to explain this phenomenon when high humidity and low existing particle concentration are applied. The downdraft-mode nucleation simulated in this study seems to fit these conditions quite well.

However, because the Lagrangian-type simulations cannot represent observations taken at a fixed location, the turbulence eddy effect shown above cannot be taken straightforwardly to explain the ANC spikes occurring at the surface. In fact, for the simulations in Figs. 7 and 11 that applied a fixed eddy size, the particles' number concentration at any given height does not exhibit fluctuations. Yet, the results in Fig. 12 suggested that the ANC spikes at the surface may occur if the properties (e.g., amplitude and frequency) of the turbulence eddy change with time. This is indeed the case as the vertical movement of turbulence eddies is known to evolve significantly with time (e.g. Feingold et al., 1998; Gibert et al., 2011). Cloud formation, in particular, can cause a large decrease in particle number. This means that the peaks of the spikes are caused by nucleation in air parcels that did not go through cloud processes, and the dips are from those that went though recent cloud formation. 
Could there be other causes of the spikes? We can address this by going back to Fig. $1 \mathrm{~b}$ and examining the detailed evolution of aerosol size spectrum. It shows a bust of nucleation-mode particles a couple of hours after sunrise. Their modal size increased gradually from around $15 \mathrm{~nm}$ at 9 a.m. to about $25 \mathrm{~nm}$ just before noon. In the meantime, the accumulation-mode particles also became more abundant while their modal size decreased from about $100 \mathrm{~nm}$ before sunrise to near $50 \mathrm{~nm}$ at noon, indicating contribution from the nucleation-mode particles. The strong nucleation in the morning is associated with low number of "pre-existing" (larger than $30 \mathrm{~nm}$ ) particles, which seems to suggest that the air mass is cleaner at this time. However, the $\mathrm{SO}_{2}$ concentration measured at a near-by air pollution monitoring station increased from $0.5 \mathrm{ppb}$ at $9 \mathrm{a} . \mathrm{m}$. to a maximum of $11 \mathrm{ppb}$ at noon then drop back to 0.5 at 1 p.m. (Fig. 2 d). This high $\mathrm{SO}_{2}$ condition is favorable to the water-sulfate binary nucleation process. The cause of this $\mathrm{SO}_{2}$ peak is uncertain, but not likely from local emissions because of the uncommon occurrence time during the day. Long-range transport is a more probable suspect. So, the case studied here might not represent typical marine PBL conditions, but a special case of the polluted air mass transported with the East Asian winter monsoon. In the afternoon, there was a sudden drop in ANC, which may also have been caused by the increase in cloudiness and thus reduced actinic flux, or simply due to a change in air-mass properties. But it is also likely related to the stronger cloud processing. One can see from Fig. 11 that ANC is much lower for the simulations with cloud formation.

It is possible that the new particles were transported down due to entrainment mixing. However, this would also mean that particle nucleation was occurring just above the PBL. Yet, the conditions of water vapor and $\mathrm{SO}_{2}$ for binary nucleation seem to be more favorable within the PBL. We recall that the event studied here was under the influence of an approaching high pressure system. According to the NOAA HYSPLIT product, the mixed-layer depth stayed relatively constant at just over $800 \mathrm{~m}$ in the morning, then decreased to below $500 \mathrm{~m}$ (indicating strong subsidence) in the afternoon. This strong subsidence tends to confine entrainment mixing. Even though the effect of entrainment mixing cannot be ruled out, it does not explain the ANC spikes as well as the mechanisms hypothesized in this study. In Fig. 1b, one can see some "strips" patterns present throughout the day, especially in the late morning and in the afternoon. Such strips correspond to the ANC spikes in Fig. 1a and are an indication of the turbulence and cloud processing effects.

Apparently, some of the detailed features in Fig. 1b have complicated causes which cannot be resolved with the idealized simulations performed in this study, and may be worthy of further investigations. Nevertheless, the ANC spikes phenomenon is likely a unique signature of the cloud and turbulence effects.
Acknowledgements. This study was supported by the Academia Sinica through the thematic project "Particulate Matter and its Environmental Impacts" as well as by projects NSC 98-2111-M002-001 and NSC 99-2111-M-002-009-MY3. Special thanks are due to Radovan Krejci for his valuable suggestions and careful examination of our results.

Edited by: R. Krejci

\section{References}

Ackerman, A. S., Toon, O. B., and Hobbs, P. V.: Dissipation of marine stratiform clouds and collapse of the marine boundary layer due to the depletion of cloud condensation nuclei by clouds, Science, 262, 226-229, 1993.

Albrecht, B. A.: Aerosols, cloud microphysics, and fractional cloudiness, Science, 245, 1227-1230, 1989.

Bigg, E. K.: A mechanism for the formation of new particles in the atmosphere, Atmos. Res., 43, 129-137, 1997.

Charlson, R. J., Schwartz, S. E., Hales, J. M., Cess, R. D., Coakley, J. A. Jr., Hansen, J. E., and Hofmann, D. J.: Climate forcing by anthropogenic aerosols, Science, 255, 423-430, 1992.

Chen, J.-P.: Theory of deliquescence and modified Köhler curves, J. Atmos. Sci., 51, 3505-3516, 1994.

Chen, J-.P. and Lamb, D.: Simulation of cloud microphysical and chemical processes using a multicomponent framework. Part I: Description of the microphysical model, J. Atmos. Sci., 51, 2613-2630, 1994.

Chen, J-.P. and Lamb, D.: Simulation of cloud microphysical and chemical processes using a multicomponent framework. Part II: Microphysical evolution of a wintertime orographic cloud, J. Atmos. Sci., 56, 2293-2312, 1999.

Clarke, A. D., Davis, D., Kapustin, V. N., Eisele, F., Chen, G., Paluch, I., Lenschow, D., Bandy, A. R., Thornton, D., Moore, K., Mauldin, L., Tanner, D., Litchy, M., Carroll, M. A., Collins, J., and Albercook, G.: Particle nucleation in the tropical boundary layer and its coupling to marine sulfur sources, Science, 282, 89-92, 1998.

Clarke, A. D., Kapustin, V. N., Eisele, F. L., Weber, R. J., and McMurry, P. H.: Particle production near marine clouds: Sulfuric acid and predictions from classical binary nucleation, Geophys. Res. Lett., 26(16), 2425-2428, 1999.

Clement, C. F., Pirjola, L., dal Maso, M., Mäkelä, J., and Kulmala, M.: Analysis of particle formation bursts observed in Finland, J. Aerosol Sci., 32, 217-236, 2001.

Coe, H., Williams, P. I., McFiggans, G., Gallagher, M. W., Beswick, K. M., Bower, K. N., and Choularton, T. W.: Behavior of ultrafine particles in continental and marine air masses at a rural site in the United Kingdom, J. Geophys. Res., 105(D22), 26891-26905, 2000.

Coffman, D. J. and Hegg, D. A.: A preliminary study of the effect of ammonia on particle nucleation in the marine boundary layer, J. Geophys. Res., 100(D4), 7147-7160, 1995.

Covert, D. S., Kapustin, V. N., Quinn, P. K., and Bates, T. S.: New particle formation in the marine boundary layer, J. Geophy. Res., D, 97, 20581-20589, 1992.

Dessens, H.: The use of spiders' threads in the study of condensation nuclei, Q. J. Roy. Meteorol. Soc., 75, 23-23, 1949. 
Dinger, J. E., Howell, H. B., and Wojciechowski, T. A.: On the sources and composition of cloud condensation nuclei in the subsidence air mass over the North Atlantic, J. Atmos. Sci., 27, 791797, 1970

Doyle, G. J.: SelfNucleation in the Sulfuric AcidWater System, J. Chem. Phys., 35, 795-799, 1961.

Easter, R. C. and Peters, L. K.: Binary homogeneous nucleation: Temperature and humidity fluctuations, nonlinearity, and aspects of new particle production in the atmosphere, J. Appl. Meteorol., 33, 775-784, 1994.

Feingold, G., S. Kreidenweis, M., and Zhang, Y.: Stratocumulus processing of gases and cloud condensation nuclei: Part I: Trajectory ensemble model, J. Geophys. Res., 103, 19527-19542, 1998.

Fuchs, N.: The mechanics of aerosols, Pergamon Press, New York, 408 pp., 1964.

Frick, G. M. and Hoppel, W. A.: Airship measurements of aerosol size distribution, cloud droplet spectra, and trace gas concentrations in the marine boundary layer, B. Am. Meteorol. Soc., 74, 2195-2202, 1993.

Gibert, F., Koch, G. J., Beyon, J. Y., Hilton, T. W., Davis, K. J., Andrews, A., Flamant, P. H., and Singh, U. N.:: Can $\mathrm{CO}_{2}$ turbulent flux be measured by lidar? A preliminary study, J. Atmos. Oceanic Tech., 28, 365-377, doi:10.1175/2010JTECHA1446.1, 2011.

Guo, H., Liu, Y., Daum, P. H., Senum, G. I. and Tao, W.-K.: Characteristics of vertical velocity in marine stratocumulus: comparison of large eddy simulations with observations, Environ. Res. Lett., 3, 045020, doi:10.1088/1748-9326/3/4/045020, 2008.

Harriton, D. and Kreidenwise, S.: Simulations of sulfate aerosol dynamicsPart I. model description, Atmos. Environ., 32(10), 16911700, 1998

Hegg, D. A., Radke, L. F. and Hobbs, P. V.: Particle production associated with marine clouds, J. Geophys. Res., 95, 917-926, 1990.

Hellmuth, O.: Columnar modelling of nucleation burst evolution in the convective boundary layer - first results from a feasibility study Part I: Modelling approach, Atmos. Chem. Phys., 6, 41754214, doi:10.5194/acp-6-4175-2006, 2006.

Jaecker-Voirol, A. and Mirabel, P.: Homogeneous nucleation in the sulfuric acid-water system, Atmos. Environ., 23, 2053-2057, 1989.

Jaecker-Voirol, A., Ponche, J. L., and Mirabel, P.: Vapor Pressures in the Ternary System Water-Nitric Acid-Sulfuric Acid at Low Temperatures, J. Geophys. Res., 95(D8), 11,857-11,863, 1990.

Kanakidou, M., Seinfeld, J. H., Pandis, S. N., Barnes, I., Dentener, F. J., Facchini, M. C., Van Dingenen, R., Ervens, B., Nenes, A., Nielsen, C. J., Swietlicki, E., Putaud, J. P., Balkanski, Y., Fuzzi, S., Horth, J., Moortgat, G. K., Winterhalter, R., Myhre, C. E. L., Tsigaridis, K., Vignati, E., Stephanou, E. G., and Wilson, J.: Organic aerosol and global climate modelling: a review, Atmos. Chem. Phys., 5, 1053-1123, doi:10.5194/acp-5-1053-2005, 2005.

Khain, A., Rosenfeld, D., and Pokrovsky, A. :Aerosol impact on the dynamics and microphysics of deep convective clouds, Q. J. Roy. Meteorol. Soc., 131, 1-25 2005.

Khosrawi, F. and Konopka, P.: Enhanced particle formation and growth due to mixing processes in the tropopause region, Atmos. Environ., 37, 903-910, 2003.
Korhonen, P., Kulmala, M., Laaksonen, A., Viisanen, Y., McGraw, R., and Seinfels, J . H.: Ternary nucleation of $\mathrm{H}_{2} \mathrm{SO}_{4}, \mathrm{NH}_{3}$, and $\mathrm{H}_{2} \mathrm{O}_{2}$ in the atmosphere, 104(D21), 26349-26353, 1999.

Korhonen, H., Lehtinen, K. E. J., and Kulmala, M.: Multicomponent aerosol dynamics model UHMA: model development and validation, Atmos. Chem. Phys., 4, 757-771, doi:10.5194/acp-4757-2004, 2004

Kulmala, M., Vehkamäki, H., Petäjä, T., Dal Maso, M., Lauri, A., Kerminen, V.-M., Birmili, W., and McMurry, P. H.: Formation and growth rates of ultrafine atmospheric particles: A review of observations, J. Aerosol Sci., 35, 143-176, 2004.

Lesniewski, T. and Friedlander, S. K.: The effect of turbulence on rates of particle formation by homogeneous nucleation, Aerosol Sci. Tech., 23, 174-182, 1995.

Levin, Z. and Cotton, W.: Aerosol pollution impact on precipitation: A scientific review, Report from the WMO/IUGG International Aerosol Precipitation Science Assessment Group, World Meteorological Organization, Geneva, Switzerland, 2007.

Marti, J.: Diurnal variation in the undisturbed continental aerosol: Results from a measurement program in Arizona, Atmos. Res., 25, 351-362, 1990 .

Marti, J. J., Weber, R. J., McMurry, P. H., Eisele, F., Tanner, D., and Jefferson, A.: New particle formation at a remote continental site: Assessing the contributions of $\mathrm{SO}_{2}$ and organic precursors, J. Geophys. Res., 102(D5), 6331-6339, 1997.

Mitra, S. K., Brinkmann, J., and Pruppacher, H. R.: A wind tunnel study on the drop-to-particle conversion, J. Aerosol Sci., 23, 245-256, 1992.

Morgan, J., Livingston, R., and Davis, C. E.: The Properties of Mixed Liquids, I. Sulfuric Acid-Water Mixtures, J. Amer. Chem. Soc., 38555-38568, 1916.

Nair, P. V. N. and Vohra, K. G.: Growth if aqueous sulfuric acid droplets as a function of relative humidity, J. Aerosol Sci., f6, 265-271, 1975.

Nilsson, E. D. and Kulmala, M.: The potential for atmospheric mixing processes to enhance the binary nucleation rate, J. Geophys. Res, 103(D1), 1381-1389, 1998.

Nilsson, E. D., Pirjola, L., and Kulmala, M.: The effect of atmospheric waves on aerosol nucleation and size distribution, J. Geophys. Res., 105(D15), 19917-19926, 2000.

Nilsson, E. D., Rannik, Ü, Kulmala, M., Buzorius, G., and O'Dowd, C. D.: Effects of continental boundary layer evolution, convection, turbulence and entrainment, on aerosol formation, Tellus, 53B, 441-461, 2001.

O’Dowd, C. D., Geever, M. Hill, M. K. Smith, M. H., and Jennings, S. G.: New particle formation: Nucleation rates and spatial scales in the clean marine coastal environment, Geophys. Res. Lett., 25(10), 1661-1664, 1998.

O’Dowd, C. D., McFiggans, G., Creasey, D. J., Pirjola, L. Hoell, C., Smith, M. H., Allan, B. J., Plane, J. M. C., Heard, D. E., Lee, J. D., Pilling, M. J., and Kulmala, M.: On the photochemical production of new particles in the coastal boundary layer, Geophys. Res. Lett., 26, 1707-1710, 1999.

Ozkaynak, H. and Thurston, G.D.: Associations between 1980 US mortality rates and alternative measures of airborne particle concentration, Risk Anal, 7, 449-461, 1987.

Perry, K. D. and Hobbs, P. V.: Further evidence for particle nucleation in clear air adjacent to marine cumulus clouds, J. Geophys. Res., 99, 22803-22818, 1994. 
Petters, M. D., Snider, J. R., Stevens, B., Vali, G., Faloona, I., and Russell, L. M.: Accumulation mode aerosol, pockets of open cells, and particle nucleation in the remote subtropical Pacific marine boundary layer, J. Geophys. Res., 111, D02206, doi:10.1029/2004JD005694, 2006.

Pirjola, L., O’Dowd, C. D., Brooks, I. M., and Kulmala, M.: Can new particle formation occur in the clean marine boundary layer?, J. Geophys. Res., 105(D21), 26531-26546, 2000.

Pruppacher, H. R. and Klett, J. D.: Microphysics of Clouds and Precipitation, Kluwer Academic Publishers, 1997.

Quinby-Hunt, M. S., Erskine, L. L., and Hunt, A. J.: Polarized light scattering by aerosols in the marine atmospheric boundary layer, Appl Opt., 36(21), 5168-5184, 1997.

Radke, L. F. and Hegg, D. A.: The shattering of saline droplets upon crystallization, J. Rech. Atmos., 6, 447-455, 1972.

Seinfeld, J. H. and Pandis, S. N.: Atmospheric Chemistry and Physics - from Air Pollution to Climate Change, 2nd Edn., John Wiley \& Sons, Inc, New York, 1203 pp., 2006.

Shaw, G.: Production of condensation nuclei in clean air by nucleation of $\mathrm{H}_{2} \mathrm{SO}_{4}$, Atmos. Env., 23, 2841-2846, 1989.

Tabata, S.: A simple but accurate formula for the saturation vapor pressure over liquid water, J. Appl. Meteor,, 12, 1410-1411, 1973.

Tolman, R. C.: The effect of droplet size on surface tension, J. Chem. Phys., 17, 333-337, 1949.

Twomey, S. and McMaster, K.: The production of condensation nuclei by crystallizing salt particles, Tellus, 7, 458-461, 1955. van der Waals, J. D.: The thermodynamic theory of capillarity under the hypothesis of a continuous variation of density, Zeit. Phys. Chem., 13, 657, 1894, (Translation by J. Rowlinson, in: J. Stat. Phys., 20, 197, 1979).

Wang, C.-C., Lee, C.-T., Liu, S. C., and Chen, J.-P.: Aerosol characterization at Taiwan's tip during ACE-Asia, Terr. Atmos. Oceanic Sci., 15, 839-855, 2004.

Wehner, B., Siebert, H., Ansmann, A., Ditas, F., Seifert, P., Stratmann, F., Wiedensohler, A., Apituley, A., Shaw, R. A., Manninen, H. E., and Kulmala, M.: Observations of turbulence-induced new particle formation in the residual layer, Atmos. Chem. Phys., 10, 4319-4330, doi:10.5194/acp-10-4319-2010, 2010.

Whitby, K. T.: The physical characteristics of sulfur aerosols, Atmos. Environ., 12, 135-159, 1978.

Yu, F.: Effect of ammonia on new particle formation: A kinetic $\mathrm{H}_{2} \mathrm{SO}_{4}-\mathrm{H}_{2} \mathrm{O}-\mathrm{NH}_{3}$ nucleation model constrained by laboratory measurements, J. Geophys. Res., 111, D01204, doi:10.1029/2005JD005968, 2006a.

Yu, F.: From molecular clusters to nanoparticles: second-generation ion-mediated nucleation model, Atmos. Chem. Phys., 6, 51935211, doi:10.5194/acp-6-5193-2006, 2006b.

Yue, G. K. and Hamill, P.: The homogeneous nucleation rates of $\mathrm{H}_{2} \mathrm{SO}_{4}-\mathrm{H}_{2} \mathrm{O}$ aerosol particles in air, J. Aerosol Sci., 10, 609614, 1979.

Zhang, R., Suh, I., Zhao, J., Zhang, D., Fortner, E. C., Tie, X., Molina, L. T., and Molina, M. J.: Atmospheric New Particle Formation Enhanced by Organic Acids, Science, 304, 1487-1490, 2004. 